\title{
Sociedad en movimiento, tejiendo paz territorial en Nariño'
}

\section{Society on the move: weaving territorial peace in Nariño}

\author{
Alba Jakeline Ruano Jiménez ${ }^{2}$ \\ Docente Universidad de Nariño, Pasto, Colombia \\ albajakeline@hotmail.com \\ https://orcid.org/0000-0003-0381-7676
}

Recibido: 29-01-2018

Aprobado: 26-10-2018

1 Este texto, a manera de artículo de reflexión, hace parte del proyecto de tesis doctoral denominada "Acción colectiva y construcción de Paz en el departamento de Nariño", trabajo que se encuentra en proceso de desarrollo como requisito para optar al título de Doctora en Estudios Sociales de la Universidad Externado de Colombia.

2 Magíster en Sociología. 


\section{Resumen}

El presente artículo aporta al reconocimiento y análisis de la experiencia de movilización social por la paz en Colombia, teniendo como estudio de caso la experiencia de movilización en Nariño, Colombia. La revisión de información de archivos y de documentos de instituciones y organizaciones sociales permite identificar particularidades de la experiencia de movilización social por la paz en Nariño. La población a través de diferentes repertorios de acción ha buscado defender y aportar al tejido de la paz, tramitar los conflictos por medios diferentes a la violencia, contribuir con el bienestar, el respeto por los derechos humanos y la justicia social. La amplia experiencia de movilización social por la paz es muestra de la fortaleza, la resistencia y el liderazgo a favor de la paz en los territorios, convirtiéndose en el principal insumo social para avanzar en la compleja tarea de la llamada construcción de paz territorial.

Palabras clave: paz; territorio; acción colectiva; tejido.

\section{Abstract}

This article contributes to the recognition and analysis of the experience of social mobilization for peace in Colombia, taking as a case study the experience of mobilization in Nariño, Colombia. The review of archival information and documents from institutions and social organizations identifies particularities of the experience of social mobilization for peace in Nariño. The population, through different repertoires of action, has sought to defend and contribute to the fabric of peace, to process conflicts by means others than violence, to contribute to welfare, respect for human rights and social justice. The wide experience of social mobilization for the peace is a sample of the fortitude, the resistance and the leadership in favor of peace in the territory, becoming the main social input to advance in the complex task of what is called "the construction of territorial peace".

Keywords: peace, territory, collective action, social fabric.

¿Cómo citar este artículo? / How to quote this article?

Ruano Jiménez, A.J. Sociedad en movimiento tejiendo paz territorial en Nariño. Sociedad y Economía, (36), 123-138.

https://doi.org/10.25100/sye.voi36.7459 


\section{Introducción}

La complejidad del conflicto armado y los hechos asociados a este, como el narcotráfico y la violencia criminal en Colombia y en cada una sus regiones, ha llevado a activar fuerzas sociales que se movilizan demandando del gobierno nacional y de los grupos en confrontación el cese del conflicto armado, la reivindicación de derechos vulnerados, el respeto por la vida, la dignidad de las personas y la justicia social. En territorios como Nariño se identifica una amplia experiencia de movilización social, que se convierten en fuerzas sociales activas y propositivas en escenarios de posconflicto.

Una de las particularidades del conflicto armado en Colombia ha sido su carácter regional. Si bien existen hechos histórico-estructurales desencadenantes del conflicto armado como: la cuestión agraria, la debilidad institucional, la desigualdad social, el uso legal e ilegal de las armas (CHCV, 2015), cada una de las regiones ha experimentado y ha vivido este conflicto con dinámicas propias. El departamento de Nariño se involucra en el escenario del conflicto armado en los años de 1980 con la presencia de los grupos guerrilleros FARC y ELN (Ávila, 2009).

Pero más allá de la presencia de estos grupos en la región, se encuentra la complejidad de las dinámicas conflictivas que se desatan a partir del proceso de expansión del conflicto armado. Los factores que favorecen dicha expansión hacia esta región del país son de carácter estructural, coyuntural e histórico, entre estos: la ubicación geoestratégica, la marginalidad, la pobreza, la desigualdad social, la débil economía, la debilidad de las instituciones estatales, la implementación del Plan Colombia en 1998, el fracaso de los acuerdos de negociación desarrollados en San Vicente del Caguán en el 2002 y el Plan Patriota en el 2003. Factores que favorecen no solamente la presencia de grupos armados insurgentes y contrainsurgentes en la frontera sur de Colombia, sino además la expansión de cultivos de uso ilícito, con mayor impacto en las regiones de frontera, cordillera y Andén Pacífico, situación que implicó la intensificación del conflicto armado.
En el 2002, la implementación de la política de Seguridad Democrática llega a esta región con una fuerte arremetida de la fuerza armada; esta política no tuvo el mismo impacto en $\mathrm{Na}-$ riño que en el resto del país, al respecto instituciones como la Misión de Observación Electoral (Núñez, 2007) y el Programa de las Naciones Unidas para el Desarrollo (PNUD, 2010) identifican el riesgo al cual estuvo expuesta la población por disputa de territorios entre las guerrillas y las fuerzas armadas estatales. Los resultados demuestran que $60 \%$ de la población nariñense estuvo expuesta a riesgos por la acción violenta de grupos armados no legales.

El porcentaje de población en riesgo por disputa aumenta del 2003 al 2007, la mayoría de disputas se presenta entre las fuerzas armadas y la policía contra las guerrillas. Adicionalmente, para líderes, lideresas y personas representantes de organizaciones sociales, el período de la política de Seguridad Democrática significó para el departamento de Nariño el aumento del pie de fuerza militar, la persecución, señalamiento y asesinato de líderes y lideresas sindicales y de defensores de los derechos humanos (Fundación Cultura Democrática, 2015).

Según datos de la Vicepresidencia de la Republica (2012), desde el 2000 se incrementa la intensidad del conflicto armado $^{3}$ en Nariño, registrando un mayor porcentaje de eventos durante 2005 (6,35\%), 2006 (6,07\%), 2010 (7,46\%), $2011(9,21 \%)$ y $2012(8,02 \%)$. Los municipios donde se presenta mayor intensidad del conflicto son Tumaco, Ricaurte, Barbacoas, Ipiales, Samaniego y Pasto.

Otros indicadores que evidencian la afectación del conflicto armado en Nariño son el número de víctimas y el número de eventos registrados. Según la Red de Información Nacional

3 La intensidad de la confrontación armada incluye las acciones de los grupos armados al margen de la ley, tales como ataques contra instalaciones de la Fuerza Pública, emboscadas, hostigamientos, eventos de terrorismo y ataques a población; y los combates por iniciativa de la Fuerza Pública en contra de todos los grupos armados al margen de la ley (Vicepresidencia de la República, 2012). 
de Servicio de Víctimas, a febrero de 2015 se registran 374.967 víctimas, en 436.780 eventos en Nariño, que lo convierten en el quinto departamento del país con mayor número de víctimas registradas; a esta situación se suma el subregistro de información desconocida hasta el momento. Los principales hechos victimizantes son: desplazamiento forzado, masacres, secuestros, homicidios, minas antipersonas y desaparición forzada, hechos que atentan contra los derechos humanos y que hacen parte de la violación del Derecho Internacional Humanitario.

Como resultado del anterior panorama, el departamento de Nariño caracterizado hasta los años de 1980 como un remanso de paz, pasa a ser una de las regiones con mayor impacto del conflicto armado, afectando las dinámicas políticas, económicas, culturales, sociales, ambientales y la vida cotidiana de sus gentes.

Es en este contexto donde tienen lugar diferentes repertorios de acción colectiva en favor de la paz. Se trata de acciones lideradas tanto por la sociedad civil y sus organizaciones como por instituciones gubernamentales, confesiones religiosas y agencias de cooperación internacional. Las diferentes experiencias se lideran en escenarios locales, departamentales y regionales, algunas con incidencia nacional. Las principales demandas se enfocan en la defensa de la vida como bien supremo, la paz como derecho constitucional, la defensa de los derechos, la denuncia de los actos de violencia armada, manifestaciones en contra del secuestro y la persecución de líderes, lideresas y defensores de derechos humanos, y de manera especial en la búsqueda de la salida negociada al conflicto armado.

Para cumplir con el objetivo del presente escrito, se desarrollan tres apartados. El primero es un acercamiento teórico conceptual de las principales categorías de análisis planteadas, entre estas: movimiento social, acción colectiva y paz desde los territorios. En el segundo apartado, se realiza un acercamiento y reconocimiento del repertorio de acción colectiva que en este caso llamaremos sociedad en movimiento tejiendo paz territorial. Finalmente, en un tercer apartado a manera de consideraciones finales, se destacan elementos que sirven como aporte para la discusión teórica, pero también práctica de lo que se ha llamado paz territorial.

\section{Un acercamiento teórico}

\subsection{Movimientos sociales y acción colectiva}

El análisis de los movimientos sociales y la acción colectiva ha girado alrededor de importantes aportes teóricos desarrollados en países de Europa, Estados Unidos y también en Latinoamérica. Entre las principales posiciones teóricas y conceptuales que se han ocupado del tema se encuentran:

1. La visión funcionalista y la teoría del comportamiento social, según la cual las disfunciones producen formas de comportamiento colectivo, algunas de las cuales se transforman en movimientos sociales (Smelser, 1989).

2. La visión marxista, según la cual los movimientos sociales se relacionan con la lucha de clases sociales y con el anhelo de la transformación de la sociedad (Tilly y Wood, 2010).

3. La teoría de la elección racional ha planteado que los movimientos sociales están asociados a "los incentivos materiales y personales que pudiera proporcionar" (Tarrow, 1998, p. 40).

4. También se ha hablado de los movimientos sociales en relación con los escenarios de oportunidades y restricciones políticas (Tarrow, 1998).

5. Más recientemente se hace mención a los nuevos movimientos sociales que, desde las visiones europea y norteamericana, se centran en el análisis del papel que cumple el actor, la acción social y la cultura en la historia (Tilly y Wood, 2010; Touraine, 2006; Melucci, 2010); y desde la experiencia latinoamericana se hace mención a los movimientos populares para diferenciar su base social de los países centrales (De Sousa Santos, 1998); en los dos casos los nuevos movimientos sociales se caracterizan como procesos completamente heterogéneos y que han estado asociados a 
las relaciones regulación-emancipación y subjetividad-ciudanía; factores que no están presentes de la misma manera en todos los nuevos movimientos sociales (De Sousa Santos, 1998).

Recogiendo los diferentes aportes de las experiencias europea, norteamericana y latinoamericanas, Archila (2003) ha definido los movimientos sociales como "aquellas acciones sociales colectivas permanentes, orientadas a enfrentar condiciones de desigualdad, exclusión o injusticia y que tienden a ser propositivas en contextos espacio-temporales determinados" (p. 74). Esta definición permite avanzar en la comprensión de las dinámicas que ha tomado el movimiento social en general y el movimiento social por la paz en particular.

Ahora bien, en América Latina las acciones colectivas y los movimientos sociales han estado asociados a las reivindicaciones de carácter social, económico, político y cultural, dimensiones que se han visto atropelladas por acciones del Estado centralizado y excluyente. Algunos de los factores que influyeron en la formación de los movimientos sociales son: el surgimiento del proletariado industrial, los procesos de industrialización, la influencia del partido comunista y la revolución Rusa, la influencia de movimientos anarquistas y la primera guerra mundial, donde se habla del primer movimiento social por la paz. En consecuencia, se destaca como principales movimientos sociales: el movimiento obrero, los movimientos campesinos e indígenas y el movimiento estudiantil, donde la huelga general es la principal forma de lucha (Bruckmann y Dos Santos, 2005). Estos movimientos toman como banderas de lucha no solamente las reivindicaciones sociales, sino también las luchas anticolonialistas, antiimperialistas, étnicas, feministas, medioambientalista, en favor de la paz y la no violencia, y más recientemente las luchas antineoliberalismo. Estas luchas hacen parte de la construcción de nuevas identidades, que no solamente responden a intereses a priori, sino a procesos históricos de reivindicación de derechos y reconocimiento de estas identidades (Archila, 2003). De igual manera, responden a transformaciones globales en el contexto político, social y cultural (De Sousa Santos, 1998) y se han convertido en parte integrante de las agendas políticas de los países del mundo y en especial de Latinoamérica.

Zibechi (2007) plantea que en América Latina existe un nuevo ciclo de resistencias, luchas y subjetividades que no encajan en los análisis eurocéntricos de la acción colectiva, ya que se evidencia el surgimiento de nuevas prácticas de radicalidad, diversas y autónomas. Para el autor, en Latinoamérica existen sociedades en movimiento donde las relaciones sociales son conmovidas y reconstruidas por actores sociales. La transformación social es posible gracias a las prácticas sociales alternativas que corresponden al tiempo y la dinámica interna de la movilización social y no necesariamente a su interacción con el sistema político. En este contexto, Zibechi (2007) plantea que el principal reto de los movimientos sociales es la expansión de su autonomía, donde la trasformación social se gestiona dentro de lo social y no a través de la conquista del poder estatal.

\subsection{Movilización social por la paz}

En relación con la movilización social en favor de la paz, se identifica el Movimiento por la Paz posguerra mundial, donde la participación e influencia del movimiento pacifista ha sido importante antes, durante y después de la primera y la segunda guerras mundiales. Entre los propósitos centrales de este movimiento ha estado el promover la coexistencia pacífica entre los países, el llamamiento a la justicia, a los derechos humanos, al fin de la violencia, la seguridad física y económica, y a partir de los años de 1970 se enfoca en la manifestación en contra del uso de armas nucleares (Ruiz, 2012; Grasa, 2015).

De igual manera, después de la guerra fría se habla de un gradual avance en la conciencia ciudadana sobre la paz, que se enfoca en el diseño y puesta en práctica de acciones para lograr un mundo más pacífico, justo y solidario. No siempre estas acciones son coyunturales o 
transitorias, por el contrario, si bien las acciones son más manifiestas en épocas de crisis, la movilización pacifista ha sido sostenida en el tiempo, aunque con diferentes formas organizativas y expresiones de movilización.

En contextos nacionales como Colombia toma relevancia el papel que han desempeñado las organizaciones de la sociedad civil en escenarios de conflicto armado interno. La sociedad con diferentes formas organizativas y mediante formas diversas de acción colectiva ha coincidido en una demanda común, que es la lucha por la paz, la salida negociada al conflicto y la construcción de una paz estable, duradera y con justicia social. Desde aquí, García (2006) ha definido el Movimiento por la Paz, como

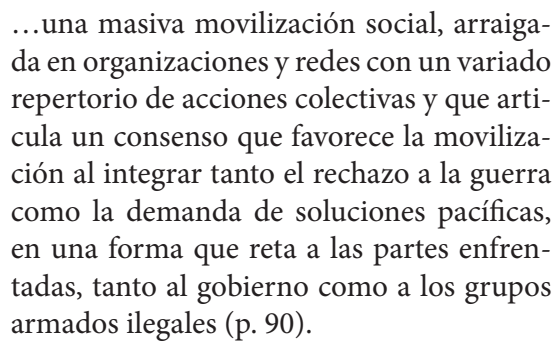

Si bien este movimiento se viene gestando desde la década de 1970, se hace más visible durante los años posteriores cuando las consecuencias del conflicto armado se incrementan, situación que motiva la activación de fuerzas sociales para manifestarse en contra de los vejámenes de la guerra y afrontar la complejidad de situaciones conflictivas que se desatan en los territorios.

Se destacan como principales características del Movimiento por la Paz en Colombia las siguientes: una movilización masiva, con un creciente y variado repertorio de acciones colectivas, un estilo de lucha colectiva no confrontacional, un fenómeno que por sus dinámicas en el contexto nacional y la relación con lo regional guarda unas características de unidad, identidad y continuidad, lo que le otorga cierto grado de sostenibilidad (García, 2006).
Otra característica son las condiciones que acompañan este movimiento: 1) la oposición a la guerra, la reivindicación de los derechos humanos, entre los cuales se destaca el derecho a la vida, la defensa del respeto a las normas del Derecho Internacional Humanitario, la defensa de la solución política negociada del conflicto armado, la promoción de la cultura y la educación para la paz y la no violencia; 2) el surgimiento de expresiones nacionales, locales, departamentales y regionales por la paz, y 3) la participación de organizaciones sociales populares (Zuluaga, 2013). A estas características se suma el carácter policlasista de las acciones colectivas, las diferenciadas concepciones de paz implícitas, la participación activa de organizaciones sociales indígenas, afrocolombianas, de la población víctima del conflicto armado y en especial de las mujeres como gestoras del Movimiento por la Paz, particularmente después de los hechos acontecidos en la toma del Palacio de Justicia en 1985.

Durante las décadas de 1980 y 1990 son más visibles las acciones colectivas de carácter nacional, cuyo punto de interés se enfoca en la salida negociada al conflicto ${ }^{4}$. En principio pareciera que el interés central de estas manifestaciones es la paz negativa (Galtung, 1990), es decir, la ausencia de violencia física; sin embargo, las demandas apuntan hacia cambios de carácter estructural y cultural, es decir, paz positiva (Galtung, 1990), que implica transformaciones sociales, políticas, económicas y culturales.

Por su parte, la Iglesia católica desempeñó un papel fundamental al incorporar la demanda de la justicia social como elemento de base para la paz. En este sentido, si bien la justicia social ha sido una de las principales demandas, estas varían en relación con las organizaciones que

4 En este período se identifican estructuras organizativas de incidencia nacional como: el Movimiento por la Defensa de los Derechos Humanos, de donde se crea el Comité Permanente por la Defensa de los Derechos Humanos (1979); los comités regionales de paz (1984); la Comisión de Paz del gobierno Betancur (1982-1984); la Red de Iniciativas por la Paz-Redepaz- (1993); La Comisión de Conciliación Nacional (1995); y la Asamblea Permanente de la Sociedad Civil por la Paz (1998). 
lideran los procesos, los tiempos y/o las coyunturas en el ámbito nacional, los grados de afectación, las particularidades de la manifestación del conflicto en las regiones y las relaciones indivisibles entre el conflicto social y armado. En consecuencia el Movimiento por la Paz jalona demandas materiales, políticas y culturales, las cuales entran a ser parte de los imaginarios y las concepciones de paz que se gestan al interior de las acciones colectivas.

El Movimiento por la Paz, así como las acciones colectivas por la paz adquieren forma en la medida en que toma rumbo el conflicto armado y los procesos de negociación entre los gobiernos y los grupos armados ilegales. En este sentido, se tiene que el movimiento se fortalece durante los períodos de demanda de negociación y decrece cuando se negocia (Zuluaga, 2013).

Al respecto se destacan algunos períodos claves durante los cuales la movilización a favor de la paz ha tomado mayor impulso, por ejemplo: el período comprendido entre 1985 y 1997, caracterizado por la intensificación del conflicto armado y su degradación, evidenciada en las formas de actuación de los grupos insurgentes, el fortalecimiento del paramilitarismo, formas encubiertas de acción de agentes del Estado y la llamada guerra sucia (Leal, 1990; Archila, 2006; García, 2006); pero la movilización decrece entre 1997 y 2003, época del proceso de negociación de paz entre el gobierno Pastrana y las FARC-EP (Zuluaga, 2013). El período entre 2004 y 2010 (con una cierta disminución de acciones durante el 2008), un período que estuvo gobernado por la política de Seguridad Democrática, con un proceso de paz entre el gobierno y los grupos paramilitares, la lucha contra el narcotráfico y el terrorismo $\mathrm{o}^{5}$, y la negativa del gobierno a reconocer la existencia del conflicto armado interno en el país; situación que implicó para el movimiento social la criminalización de sus

5 La lucha antinarcóticos y antiterrorista liderada por Estados Unidos se intensifica después del ataque a las Torres Gemelas el 11 de septiembre de 2001. acciones, el señalamiento, la persecución y el asesinato de algunos de sus líderes (Zuluaga, 2013; Villarraga, 2013).

En medio de las dificultades, desde los años 2010 y 2012 la movilización social toma relevancia en el ámbito nacional, y en especial en los contextos locales y regionales, con la participación de grupos sociales como población víctima, jóvenes, mujeres, pueblos indígenas y comunidades negras.

Este panorama muestra una amplia movilización social en favor de la paz, que evidencia la capacidad organizativa, de acción social e incidencia política de la sociedad civil. Sin embargo, son grandes los retos que afrontan estas iniciativas y con ellas el análisis de los movimientos y la acción colectiva en favor de la paz; uno de ellos es el carácter polisémico del concepto, que ha llevado a que los diferentes actores, llámense sociedad civil, organizaciones sociales, Estado y sus instituciones, grupos insurgentes o confesiones religiosas entre otras, entiendan, trabajen y demanden un tipo particular de paz. Este ha sido un reto, no solo para los movimientos sociales, sino también para los gobiernos y para la sociedad civil en general.

En el marco de la llamada paz territorial', se pone especial énfasis en las características específicas de las regiones y en las condiciones sociales, políticas, económicas y culturales existentes en cada una de ellas. De allí la importancia del reconocimiento y la visibilización de los acumulados sociales en términos organizativos y de acción colectiva existentes en cada uno de los territorios, experiencias que nos acercan a una visión territorial de paz.

6 Término que se populariza en el marco del proceso de negociación entre el gobierno de Juan Manuel Santos $\mathrm{y}$ el en ese momento grupo guerrillero FARC-EP. Desde este escenario, Jaramillo (2014) asocia como elementos importantes de la paz territorial la presencia institucional, no solamente en sentido de entidades, sino también de un conjunto de prácticas y normas que regulen la vida pública, y el enfoque en derechos, principalmente de las víctimas. 


\section{Tejiendo paz desde los territorios}

Se ha hablado mucho de construcción de paz como categoría de análisis de alta complejidad por la multiplicidad de elementos y situaciones que implica en términos estructurales, culturales, simbólicos (Galtung, 1990), individuales, colectivos (Lederach, 2008; Fisas, 2002; Paladini, 2011) y políticos, solo para nombrar algunas corrientes. En el mismo orden de ideas, desde los territorios se entiende la paz desde su carácter polisémico y de alta complejidad tanto para su análisis como para avanzar en la praxis de la misma. Sabogal (2016) plantea abordar la paz desde la concepción propia de los territorios, de allí propone utilizar tejido en lugar de construcción; el profesor menciona que "el tejido da la idea de complejidad y de paciencia y recoge una forma de pensamiento ancestral... el tejido de la paz implica condiciones adecuadas a una vida buena, bienvivir en los territorios" (p. ), en consecuencia, y ante la multiplicidad de experiencias e iniciativas de paz institucionales y comunitarias, el tejer la paz implica poner en diálogo estas experiencias, las potencialidades socioculturales, las complejidades y particularidades del conflicto armado y la presencia de otras conflictividades dentro de cada territorio.

El departamento de Nariño es un territorio de amplia experiencia en procesos de movilización social. Durante los años de 1980 y 1990 la movilización social estaba asociada a la exigencia y la lucha por la reivindicación de derechos relacionados con la educación, el sector agropecuario, la malla vial, los salarios, las tarifas de los servicios públicos, y con menor impacto movilizaciones relacionadas con el secuestro y muerte de líderes sindicales y en favor de la paz (Muñoz y Mosquera, 2001); una de las razones que justificaba esta última situación es la aún incipiente manifestación de hechos relacionados con el conflicto armado y el alto escepticismo de la población frente a la paz.
En el contexto nacional las acciones en favor de la paz, tanto institucionales como sociales, se hacen evidentes a la par con las manifestaciones del conflicto armado (décadas de 1970 y 1980). En el departamento de Nariño este tipo de acciones colectivas comienzan a manifestarse solo a finales de la década de 1990, cuando el conflicto armado se intensifica en esta región del país. Época en la cual la sociedad nariñense se une al clamor nacional de la búsqueda de la paz, a la solución pacífica del conflicto armado y a los hechos relacionados con este, como la extensión de los cultivos de uso ilícito y las dinámicas del narcotráfico.

En este escenario se identifican entre procesos más visibles: Samaniego Territorio de Paz (1998), II Laboratorio de Paz, Paz y Desarrollo en el Macizo Colombiano (2001), la Surcolombianidad (2002), la Constituyente de Nariño por un Mandato Popular (2002), Pacto Local por la Paz (2004-2007), el Programa "Sí se puede" (2006 -2012), Teatro por la Paz en Tumaco (2009), Minga por la Paz de Nariño (2012), Casa de la Memoria de Tumaco (2013), Agenda de Paz de Nariño (2013 -2015), Minga Nariñense por la Paz (2014), Plan Estratégico para la Paz (2015).

Los procesos de la Surcolombianidad, la Constituyente de Nariño por un Mandato Popular, el II Laboratorio de Paz y Paz y Desarrollo en el Macizo Colombiano se destacan por la articulación de intereses institucionales y sociales en razón de la construcción de la paz. La Surcolombianidad, que surge del interés por construir paz desde la región, fue una propuesta liderada por los gobernadores del sur de Colombia (Nariño, Cauca, Putumayo, Huila, Tolima, Caquetá) en el 2002. En principio, el objetivo central era adelantar diálogos con el entonces presidente Andrés Pastrana sobre el tema de erradicación de cultivos de uso ilícito7, a quien se propone el Plan Alterno (Plan Sur) que buscaba presentar alternativas a la implementación del Plan Co-

7 Durante la administración de Andrés Pastrana (1998 -2002) la implementación del Plan Colombia implica la erradicación de cultivos de uso ilícito mediante la fumigación con glifosato. 
lombia y las fumigaciones aéreas que estaban causando tanto daño a la región (Barreto, 2009). Sin embargo, pese a las gestiones adelantadas por este grupo de gobernadores no se avanzó en el tratamiento certero de esta situación. La propuesta avanza en el gobierno de Álvaro Uribe, pero esta vez se formulan otros objetivos enfocados en soluciones a los impactos del conflicto armado en la región suroccidental de Colombia, objetivo que solo será posible con la participación activa de la sociedad civil. Caballero (2011) plantea que "luego de las elecciones en el año 2003, el escenario de la Surcolombianidad cambió, ya que en los departamentos más comprometidos con esta propuesta solo hubo continuidad política en Nariño, en tanto que en Tolima y Cauca asumieron sectores políticos que no tenían compromiso con la misma" (2011, p. 144). De este contexto se deduce que uno de los inconvenientes para la construcción e integración de región es el cambio de administraciones locales, departamentales y nacionales, convirtiendo el proceso en una dinámica de debate electoral y perdiendo de vista el interés por la construcción de región.

En el mismo marco de la Surcolombianidad en el 2002, durante la Segunda Cumbre de Gobernadores del Suroccidente, la Gobernación de Nariño propuso a los mandatarios de Huila, Tolima, Caquetá, Putumayo y Cauca, la realización de Asambleas Constituyentes Departamentales. El propósito de esta iniciativa era "elevar la conciencia política de los pueblos en el sentido de darles un mayor conocimiento en los temas públicos para que sean capaces de ejercer su derecho a opinar y formular propuestas transformadoras en el ámbito local, departamental y nacional" (PNUD, 2005).

Según Ríos Correa (2010), el desarrollo de las Asambleas Constituyentes desde lo local es asumido por la sociedad civil y se constituyen en espacios de generación de dinámicas de participación ciudadana. Este ejercicio planeó un nuevo rumbo hacia la democracia y el ejercicio del poder. Esta experiencia significo para Nariño la activación de fuerzas sociales y el fortalecimiento de procesos organizativos con visión socio-política y reconocimiento por los territorios, dando viabilidad a las luchas sociales por la reivindicación de derechos y mejoramiento de las condiciones de vida. Las dificultades para materializar este proceso fueron de carácter económico, pero la experiencia deja un gran legado en relación con la formación política de la sociedad civil y la estructuración de espacios de participación social.

El II Laboratorio de Paz en el Macizo Colombiano es otra experiencia que se enfoca en la construcción de paz desde los territorios. Como Laboratorio de Paz tiene como fin "propiciar la construcción colectiva de las condiciones para una paz duradera y la convivencia pacífica basada en una vida con dignidad y oportunidades para todos los habitantes" (Asopatía, CRIC, Acción Social y Unión Europea, 2008, p.). En el Departamento de Nariño esta propuesta es sostenida por una estructura bicéfala conformada por el Consejo Regional Indígena del Cauca (CRIC) y la Asociación de Municipios de la Región del Alto Patía (Asopatía). Este proceso se entiende como un "experimento en la construcción de paz" (Barreto, 2009) y de procesos de desarrollo alternativo desde las bases sociales.

Barreto (2009) plantea que los Laboratorios de Paz se fundamentan en tres elementos. Primero, representan una forma de construcción de paz desde las regiones es decir la descentralización de la resolución de conflictos. Segundo, se parte de un concepto de paz y una visión del conflicto que involucran elementos como pobreza, y exclusión social, económica y política como causas estructurales del conflicto y la violencia; en este sentido el Laboratorio de Paz se convierte en una propuesta de desarrollo alternativo más participativo, equitativo y con inclusión social. Y tercero, la filosofía de los laboratorios se fundamenta en la participación de la sociedad civil; estos escenarios buscan dar voz a aquellos grupos poblacionales más vulnerables y quienes históricamente han sido excluidos como los campesinos, los pueblos indígenas, las comunidades negras, las mujeres y los jóvenes, entre otros. 
En el contexto municipal es interesante y relevante la experiencia de la movilización social en Samaniego, en 1998 con el proceso Samaniego Territorio de Paz y en el período comprendido entre 2004 y 2007 el Pacto Local por la Paz, escenarios liderados por la sociedad civil en articulación con la administración municipal. Muestra del liderazgo, interés e iniciativa de la sociedad por la defensa del territorio, la gobernabilidad y el respeto por los derechos humanos.

Una de las acciones puntales del Pacto Local por la Paz fue presentar una carta abierta de los pobladores del municipio y sus instituciones a los grupos armados presentes en la zona. En ella se declaraban neutrales y autónomos frente al conflicto armado, con compromisos de buscar otras formas de resolver los conflictos sin la confrontación violenta y generar una cultura de tolerancia; exigían la promoción de los Derechos Humanos y del Derecho Internacional Humanitario, la participación, la democracia, la competitividad; solicitaban declarar libres del conflicto algunos espacios de interés ciudadano como el hospital, puestos de salud, escuelas, la alcaldía y la vía Túquerres-Samaniego (Montufar, 2005). Uno de los grandes logros de este proceso fue el desminado humanitario, que gracias a la fuerte movilización social, logró el aval tanto del gobierno nacional como de los actores armados ilegales presentes en el territorio.

Las mencionadas experiencias han servido de fundamento para continuar tejiendo acciones por la paz sociales e institucionales, que en el marco del proceso de negociación entre el gobierno nacional de Juan Manuel Santos (20102014) y los grupos insurgentes de ese momento (FARC-EP y ELN), articulan esfuerzos con el objetivo de apoyar y acompañar tanto las dinámicas de las negociaciones como la preparación de escenarios y agendas de paz propias de los territorios. Entre estos procesos se identifican: Minga por la Paz de Nariño, Minga Nariñense por la Paz y Mujeres Nariñenses por la Paz, procesos apoyados en organizaciones de la sociedad civil donde confluyen hombres y mujeres de población campesina, indígena, comunidades negras y organizaciones de víctimas.

En este mismo escenario se han construido agendas territoriales para la paz con la participación de organizaciones de la sociedad civil, instituciones gubernamentales y agencias de cooperación internacional. La sociedad nariñense ha participado de manera activa en la elaboración de dos agendas territoriales: la Agenda Común para la Paz desde los Territorios, liderada por CDPAZ-Planeta Paz y Oxfam (2014-2017) y Agenda de Paz Nariño, iniciativa ciudadana e interinstitucional de construcción de una visión socio-política y territorial de paz, liderada por el PNUD, la Gobernación de Nariño (2013-2015), las Diócesis de Ipiales, Tumaco y Pasto, la Agencia de Desarrollo Local (ADEL) y ONU Mujeres.

Además de estos procesos departamentales y regionales, en cada uno de los municipios, en especial donde el conflicto armado ha causado mayores impactos, la ciudadanía se organiza y se moviliza como forma de resistencia frente a las diferentes acciones de violencia. En Tumaco, por ejemplo, se destacan procesos como Teatro por la Paz de Tumaco y la Casa de Memoria, liderados por Pastoral Social, la Diócesis de Tumaco y la sociedad civil, donde se identifica amplia participación de jóvenes, mujeres y población víctima del conflicto armado. En el municipio de Samaniego, de la mano con Minga por la Paz de Nariño, se lideran procesos como el Plan de Vida de la Montaña, Espacio Educativo para la Paz y el Buen Vivir, y la Asociación del Pacto Local de Paz del Chinchal. En el municipio de Santacruz, se identifican iniciativas como: el desminado humanitario del Sande y la propuesta Paz Duradera de Santacruz.

Cada una de las experiencias mencionadas se asocia directamente con el contexto socio-político que los rodea y que está estrechamente relacionado con las dinámicas conflictivas en los territorios, de allí su repertorio de acción y las demandas que defienden. A continuación se presentan algunas particularidades de cada uno de los procesos mencionados. 
Minga por la Paz de Nariño se reconoce como la confluencia de diversas organizaciones que se reconocen en el objetivo común de la construcción de paz desde y para los territorios. Su compromiso con la paz va más allá de la negociación y acuerdos entre el gobierno y los grupos armados ilegales, la propuesta que se defiende es un proceso integral de atención a las situaciones generadoras de conflictividades en los territorios, situaciones asociadas a las desigualdades sociales, la precaria e ineficiente presencia del Estado en los territorios, las situaciones de pobreza extrema y la explotación indiscriminada de los recursos naturales, entre las más mencionadas. Este proceso incluye iniciativas territoriales concretas como la consolidación de los territorios campesinos agroalimentarios, los planes de vida con campesinos y con comunidades indígenas, los procesos de desminado humanitario, los pactos locales dentro de los territorios, y la consolidación de un espacio educativo para la paz y el buen vivir (Minga por la Paz de Nariño, 2012; 2015). Este proceso recoge y apoya todas estas iniciativas, siendo la principal demanda una paz integral, con los aportes y la participación de la sociedad civil y sus organizaciones de base social.

Minga Nariñense por la Paz es una propuesta de los sectores sociales, democráticos y de la izquierda nariñense que se conforma con el fin de apoyar electoralmente el proceso de paz entre el gobierno nacional y las FARC-EP. Es un escenario de confluencia entre movimientos, organizaciones y procesos sociales, con partidos políticos alternativos y de izquierda, demócratas y progresistas e independientes. Tiene como objetivo "trabajar por la paz con justicia social, la participación y estímulo a las movilizaciones sociales y la acción política unitaria para alcanzar el buen vivir en Nariño" (Minga Nariñense por la Paz, 2014, párr. 3). El trabajo que se lidera articula objetivos sociales, políticos y de participación electoral.

Mujeres Nariñenses por la Paz es un colectivo de mujeres a favor de la salida negociada al conflicto armado colombiano. Se autodenominan nariñenses, sin embargo su radio de acción, en la gran mayoría, se concentra en la ciudad de Pasto. Cuenta con el apoyo de la organización nacional Mujeres por la Paz. Entre sus objetivos se encuentran generar procesos de empoderamiento social, en particular de las mujeres, frente a los Acuerdos de Paz entre el gobierno nacional, las FARC y el ELN; desarrollar actividades pedagógicas sobre los derechos humanos y construcción de paz; acompañar el proceso de implementación de los Acuerdos de Paz con las FARC y las mesas de negociación con el ELN; ejercer veeduría ciudadana a la implementación de los Acuerdos de Paz; tejer redes de apoyo a los procesos de paz y el cuidado integral de la naturaleza; generar investigación para fortalecer la memoria histórica del conflicto y sus víctimas.

Agenda Común para la Paz desde los Territorios. Es un proceso de construcción colectiva de diferentes organizaciones sociales y populares de cinco regiones del país. Encuentros desarrollados durante tres años (2014-2017) para hablar sobre sus ejercicios territoriales de construcción de paz y los escenarios que se abren en los territorios con la solución negociada del conflicto (CDPAZ-Planeta Paz y Oxfam, 2017). El departamento de Nariño se articula a esta iniciativa con diferentes organizaciones sociales, entre ellas: Minga Nariñense por la Paz y el Centro de Investigaciones La Gotera. Esta Agenda se constituye en un referente y una herramienta social y pedagógica en el escenario del posacuerdo, entre otras razones porque permite entender desde las voces territoriales cómo el conflicto social y armado transformó los territorios y lo que implica social y territorialmente la desactivación de las dinámicas de guerra; también recoge las experiencias de acción colectiva en nombre de la paz y la multiplicidad de actores, líderes y lideresas, personas empoderadas de procesos territoriales con alto contenido identitario y cultural, elementos centrales para la formulación de programas y políticas que demandan la construcción de paz territorial.

Agenda de Paz Nariño es un proceso sociopolítico departamental, desarrollado entre 2013 y 2015, cuya premisa orientadora fue "la paz en Nariño es una tarea conjunta, permanente 
e impostergable" (Gobernación de Nariño, Diócesis de Pasto, Ipiales y Tumaco, Programa de las Naciones Unidas para el Desarrollo, 2014). Este proceso implicó un conjunto de actividades encadenadas, continuas y complejas, que involucró la participación activa de la sociedad nariñense y que no se agota en un momento coyuntural o transitorio. Con este proceso se dinamizaron las fuerzas sociales presentes en cada uno de los 64 municipios de Nariño, donde se reconoció el territorio como el potencial político, identitario y afectivo construido por la sociedad nariñense en su relación con el medio físico-natural y socio-cultural. Entre los elementos centrales que se rescatan en este proceso se encuentra el reconocimiento de la tradición agraria y campesina del departamento y en este contexto el rescate de la autonomía territorial, el tejido social, la conservación, la protección de los lugares sagrados y la madre tierra. De la misma manera, se reconoce y valora que la paz se teje desde los diferentes escenarios de la vida cotidiana, en las relaciones que se establecen en los diferentes espacios del compartir social, en la familia, la escuela, el trabajo, la comunidad, las organizaciones y las instituciones (Agenda de Paz Nariño, 2016).

Teatro por la Paz Tumaco es una iniciativa que surge en 2009, producto de una obra de teatro llamada La Madre, presentada por jóvenes tumaqueños en Quibdó, Chocó, en el 2008, como homenaje a la hermana Yolanda Cerón, asesinada el 19 de septiembre de 2001 en el centro de la ciudad de Tumaco, hecho atribuido a grupos paramilitares (Bloque Libertadores del Sur). Esta experiencia es apoyada por el Obispo de Tumaco, Gustavo Girón Higuita, quien considera que el teatro podría ser la salida a la violencia y al silencio temeroso que reinaba en esta ciudad debido a tantos hechos del conflicto armado. Ante la crítica situación de orden público en la ciudad de Tumaco, esta experiencia artística se considera un dispositivo de gran importancia para motivar a la gente a resistir pacíficamente y a la vez, no ser pasiva frente al conflicto armado. Una sociedad en movimiento en busca de soluciones pacíficas a los conflictos y con grandes capacidades para la acción colectiva (Teatro por la Paz en Tumaco, 2014; Centro de Memoria Histórica, 2017).

Casa de la Memoria es un espacio físico de acogida personal para las víctimas y para personas e instituciones que desean trabajar por la paz. Quincenalmente la Casa de la Memoria ofrece talleres a equipos de docentes de todas las instituciones educativas de Tumaco en educación para la paz. Varios grupos de víctimas que se reúnen semanalmente allí y van tejiendo lazos de amistad. También se brinda acompañamiento psico-social. La casa cuenta con espacios físicos simbólicos y culturales como el santuario para las víctimas, la sala de acciones para la vida y el Centro de documentación. Entre sus objetivos se encuentran la denuncia de violaciones a los derechos humanos, la lucha por la dignificación de las víctimas y la coordinación de acciones para exigir al gobierno acciones en defensa de la vida (Casa de la Memoria Tumaco, 2017).

Espacio Educativo para la Paz y el Buen Vivir. Centro de formación y articulación de las iniciativas territoriales y de participación comunitaria. Surge como una respuesta comunitaria, institucional, de cooperación internacional y gremial para la resolución pacífica y democrática de conflictos, la construcción o tejido territorial integral de paz y de integración de las dinámicas productivas, comerciales, sustentables, interculturales del territorio con la academia, especialmente en la formación técnica, tecnológica y universitaria. Tiene como objetivo consolidarse como espacio epistemológico y un espacio físico, dedicado a la investigación, acción, participación y formación permanente, como una forma de ser parte de la urdimbre de la paz y la vida en los territorios, pero también como un aporte integral a ser parte de los posacuerdos para la terminación del conflicto armado, y el trámite y gestión de otras problemáticas (Montufar, 2017).

Como se puede leer, los procesos y las agendas son experiencias de movilización social en favor de la paz, donde se destacan propuestas lideradas por la sociedad civil así como también 
procesos desarrollados con acompañamiento y liderazgo de instituciones públicas y privadas. De igual forma, se tiene que dichos procesos son diferentes en razón de los radios de acción, el ejercicio de los liderazgos, las formas de participación y las coyunturas socio-políticas que los rodean. En este sentido, estamos frente a un ejemplo de sociedades en movimiento (Zibechi, 2007), con unas dinámicas de movilización social por la paz con diversidad de objetivos, demandas y repertorios de acción; muestra de que la sociedad no deja de moverse, "porque detenerse implica caer en el abismo de la negación, dejar de existir" (Zibechi, 2007, p. 16), y lo que encontramos en los territorios son sociedades que a pesar de los golpes recibidos a causa del conflicto armado existen y cuentan con capacidades individuales y colectivas, que las hace activas y propositivas.

Esta diversidad de acciones colectivas por la paz, a través de sus particulares formas de lucha, buscan cambios sociales, políticos, económicos dentro de sus territorios, cambios que hacen parte de su visión territorial de paz, una paz que implica volver sobre la reconstrucción del tejido social y sobre una profunda reforma política y económica que garantice la satisfacción de las necesidades humanas hasta donde sea socialmente posible y los conflictos se gestionen por medios diferentes a la violencia.

\section{Consideraciones finales}

En Colombia el debate de la movilización social ha estado asociado a luchas reivindicativas de sectores sociales, sindicales, campesinos y comunidades indígenas; un debate mediado por la situación social del país y los contextos políticos que han tenido lugar. En este contexto se reconoce la amplia movilización social por la paz como un proceso complejo donde confluyen heterogeneidad de iniciativas que demanda una paz asociada, en principio, a la salida negociada del conflicto armado y hechos asociados; Pero, en los contextos regionales la paz toma un carácter polisémico, relacionado con las particularidades del conflicto armado y sus consecuencias en cada uno de los territorios, lo que implica el reconocimiento de las dimensiones sociales, culturales y simbólicas como elementos de reconstrucción de identidades en cada territorio.

Quizá la única situación positiva que se deriva de la compleja dinámica del conflicto armado en Colombia es la activación de fuerzas sociales en favor de la paz. Grupos poblacionales escasamente visibles entre ellos jóvenes, mujeres, comunidades negras, indígenas y campesinas han protagonizado y liderado interesantes iniciativas para tejer la paz en sus territorios afectados por la violencia criminal y armada, el narcotráfico, los cultivos de uso ilícito y el desplazamiento forzado, entre otras conflictividades. En este contexto el carácter territorial de la paz está en articular las diferentes políticas nacionales enfocadas en la construcción de paz, con las acciones colectivas y las agendas regionales, donde la sociedad ha desarrollado interesantes propuestas como conocedora de las dinámicas propias de cada uno de los territorios.

Tejer la paz territorial implica un proceso complejo, que requiere dedicación, creatividad, paciencia, constancia y un trabajo articulado; y el trabajo que se ha desarrollado en favor de la paz ha requerido la articulación de fuerzas sociales e institucionales. De allí la importancia de evocar el pasado, analizar los contextos, las situaciones, las fortalezas y también las debilidades, buscando estructurar procesos más sólidos y fortalecidos como insumo que contribuya a avanzar no solamente en la salida negociada al conflicto, sino además en el tejido de la convivencia, la reconciliación, la recuperación de la confianza y la búsqueda y/o creación de estrategias de resolución de conflictos a través de medios no violentos.

Para finalizar, es necesario reconocer que las propuestas de paz que se gestan tanto desde los gobiernos nacionales como las iniciativas sociales regionales, no pueden ser consideradas tablas de salvación a todos los conflictos que afrontan las regiones. En este contexto, es necesario el fortalecimiento organizativo y participativo de la sociedad civil, con visión colectiva y de construcción del territorio, con propuestas y proyectos que sobrepasen lo productivo, avanzando hacia la reconstrucción del tejido social, 
el respeto y la protección de los derechos humanos, el reconocimiento de la diversidad y la diferencia, la lucha por la justicia, la igualdad y la equidad social, todos estos elementos necesarios para crear rutas hacia un "desarrollo" pensado desde y para las comunidades.

\section{Referencias}

Agenda de Paz Nariño. (2016). Visión Sectorial de la Paz para Nariño. Cartilla $N^{\circ} 3$. Pasto, Nariño: Programa de las Naciones Unidas para el Desarrollo PNUD, ONU Mujeres, Agencia de Desarrollo Local - ADEL.

Archila, M. (2003). Idas y Venidas, Vueltas y Revueltas. Protesta social en Colombia 1958 - 1990. Bogotá, Colombia: Instituto Colombiano de Antropología; Centro de Investigación y Educación Popular.

Archila, M. (2006). Los movimientos sociales y las paradojas de la democracia en Colombia. Controversia, (186), 8-32. Recuperado de https://www.revistacontroversia.com/index. php?journal=controversia\&page $=$ article\&op $=$ view \&path\%5B\%5 $=175 \&$ path\%5B $\% 5 \mathrm{D}=0$

Asopatía, CRIC, Acción Social y Unión Europea. (2008). Banco de experiencias significativas para la paz y la convivencia. II Laboratorio de Paz y desarrollo, Región Macizo Colombiano. Alto Patía, Colombia: Informe Impreso.

Ávila, A. (2009). Conflicto armado en Nariño: Reconfiguración del poder regional de los actores armados. Bogotá, Colombia: Corporación Nuevo Arco Iris.

Barreto, M. (2009). El Laboratorio de Paz del Cauca y Nariño: ¿Una salida indígena para la paz en Colombia? En J. Restrepo y D. Aponte (Eds.), Guerra y Violencias en Colombia. Herramientas e Interpretaciones (pp. 545-585). Bogotá, Colombia: Pontificia Universidad Javeriana.

Bruckmann, M. y Dos Santos, T. (2005). Los movimientos sociales en América Latina: un balance histórico. Recuperado de http://bibliotecavirtual.clacso.org.ar/ar/libros/reggen/ppl3.pdf

Caballero, H. (2011). El Laboratorio de Paz II en el Macizo Colombiano Alto Patía. Versión de un participante. En V. Soto (Eds.), Construir Paz. Aportes desde la Universidad Nacional de Colombia (pp. 137-163). Bogotá, Colombia: Cátedra Manuel Ancízar Universidad Nacional de Colombia.

Casa de la Memoria Tumaco. (2017). Quienes Somos. Recuperado de https://casamemoriatumaco.org/ quienes-somos/

CDPAZ-Planeta Paz y Oxfam. (2017). Agenda Común para la Paz desde los Territorios. Bogotá, Colombia: Planeta Paz y OXFAM.

Centro de Memoria Histórica. (2017). Teatro por la Paz Tumaco. Consultado en http://www. centrodememoriahistorica.gov.co/en/narino/teatro-por-la-paz-registro

CHCV -Comisión Histórica del Conflicto y sus Víctimas-. (2015). Contribución al entendimiento del conflicto armado en Colombia. Recuperado de http://static.elespectador.com/ archivos/2015/02/1952328280f79f83ccb8b9929c8d8fa5.pdf

De Sousa Santos, B. (1998). De la mano de Alicia: Lo Social y lo Político en la Posmodernidad. Bogotá, Colombia: Siglo del Hombre Editores.

Fisas, V. (2002). La paz es posible. Una agenda para la paz del siglo XXI. Barcelona, España: Plaza y Janés Editores S.A 
Fundación Cultura Democrática. (2015). Seminario Los procesos de paz en Colombia: experiencias y propuestas desde las regiones. Recuperado de http://biblioteca.ucp.edu.co/Descargas/core/ documentos/1.pdf

Galtung, J. (1990). Cultural Violence. Journal of peace Research, 27(3), 291-305. Recuperado de http:// www2.kobe-u.ac.jp/ alexroni/IPD\%202012/2012_2/Cultural\%20Violence\%2O(Galtung).pdf

García, M. (2006). Movimiento por la Paz en Colombia (1978-2003). Bogotá, Colombia: Ediciones Antropos Ltda.

Gobernación de Nariño, Diócesis de Pasto, Ipiales y Tumaco, Programa de las Naciones Unidas para el Desarrollo - PNUD. (2014). Agenda de Paz de Nariño. "Construir la paz en Nariño es una tarea conjunta e impostergable". Documento de Trabajo.

Grasa, R. (2015). Un factor y actor imprescindibles. Revista Por la Paz: Los pacifistas durante la primera guerra mundial, (24), (editorial). Recuperado de http://www.icip-perlapau.cat/numero24/pdf-esp/ Per-la-Pau-n24-ESP.pdf

Jaramillo, S. (2014). La Paz Territorial. Recuperado de http://equipopazgobierno.presidencia.gov.co/ prensa/declaraciones/Paginas/paz-territorial-sergio-jaramillo-alto-comisionado-paz-proceso-paz. aspx

Leal, F. (1990). Estructura y coyuntura de la crisis política. En F. Leal y L. Zamosc (Eds.), Al filo del caos. Crisis política en la Colombia de los años 80 (pp. 17-35). Bogotá, Colombia: Tercer Mundo Editores.

Lederach, J. (2008). La imaginación moral. El arte y el alma de construir la paz. Bogotá, Colombia: Grupo Editorial Norma.

Melucci, A. (2010). Acción Colectiva, vida cotidiana y democracia. Ciudad de México, México: Colegio de México, Centro de Estudios Sociológicos.

Minga Nariñense por la Paz. (2014). Documentos de trabajo. Pasto, Colombia: Minga Nariñense por la Paz.

Minga por la Paz de Nariño. (2012). Documentos de trabajo. Pasto, Colombia: Minga por la Paz de Nariño.

Minga por la Paz de Nariño. (febrero de 2015). Documento de relatoría de Asamblea General de Minga por la Paz de Nariño. Pasto, Colombia: Minga por la Paz de Nariño.

Montufar, H. (10 de noviembre del 2005). Pacto Local de Paz. Recuperado de http://www. saliendodelcallejon.pnud.org.co/buenas_practicas.shtml? $\mathrm{x}=7621$

Montufar, H. (2017). Construccion y puesta en marcha del Espacio Educativo para la Paz y el Buen Vivir en Samaniego Subregion Abades. Documento de trabajo. Samaniego, Nariño: Instituto Sur Alexander Von Humboldt ISAIS.

Muñoz, J. y Mosquera, J. (2001). Trayectoria de los Movimientos Sociales en Nariño, periodo 1994-2000 (tesis de pregrado). Universidad de Nariño, Pasto, Colombia.

Núñez, M. P. (2007). Contexto de violencia y conflicto armado. Pasto, Nariño: Misión de Observación Electoral, Observatorio de conflicto armado, Corporación Nuevo Arco Iris.

Paladini, B. (2011). Construcción de paz, transformación de conflictos y enfoques de sensibilidad a los contextos conflictivos. Recuperado de http://www.bivipas.unal.edu.co/bitstream/10720/657/1/ Arte\%20M\%C3\%B3dulo\%205\%20_Hojas\%2Ointernas.pdf 
PNUD -Programa de las Naciones Unidas para el Desarrollo-. (2005). Constituyente de Nariño, por un Mandato Popular. Recuperado de http://www.saliendodelcallejon.pnud.org.co/buenas_practicas. shtml? $\mathrm{x}=7623$

PNUD -Programa de las Naciones Unidas para el Desarrollo-. (2010). Nariño: Análisis de la Conflictividad. Recuperado de https://info.undp.org/docs/pdc/Documents/COL/00058220_ Analisis\%20conflictividad\%20Nari\%C3\%B10\%2OPDF.pdf

Ríos, C. (2010). Las asambleas constituyentes locales y regionales como alternativa para la gobernabilidad y la paz en Colombia (tesis de maestría). Universidad Pontificia Bolivariana, Medellín, Colombia. Recuperado de https://repository.upb.edu.co/bitstream/handle/20.500.11912/95/asambleas\%20 constituyentes.pdf? sequence $=1$

Ruiz, J. (2012). El movimiento pacifista en el siglo XXI: nuevos principios y estrategias. Revista Latinoamericana Polis, 14(2006), 1-22. Recuperado de http://polis.revues.org/5213.10.4000/polis.5213

Sabogal, J. (2016). El tejido de la paz territorial en el Post Acuerdo. Pasto, Colombia: Universidad de Nariño.

Smelser, N. J. (1989). Teoría del comportamiento social. Ciudad de México, México: Fondo de Cultura Económica.

Tarrow, S. (1998). El poder en Movimiento. Los movimientos sociales, la acción colectiva y la política. Madrid, España: Alianza Editorial.

Teatro por la Paz en Tumaco. (3 de mayo del 2014). Observatorio Pacífico y Territorio. Recuperado de https://pacificocolombia.org/teatro-por-la-paz-en-tumaco/

Tilly, Ch. y Wood, J. (2010). Los movimientos sociales, 1768-2008. Desde sus orígenes a Facebook. Barcelona, España: Editorial Crítica.

Touraine, A. (2006). Los movimientos sociales. Revista Colombiana de Sociología, 27(2006), 255-278.

Vicepresidencia de la Republica. (2012). Estadísticas históricas del Conflicto armado y la situación humanitaria en el Departamento de Nariño. Bogotá, Colombia: Observatorio del Programa Presidencial de DH y DIH.

Villarraga, Á. (2013). El movimiento ciudadano y social por la paz en Colombia. En Á. Villarraga (Comp.), Movimiento ciudadano y social por la paz. Biblioteca de la Paz. Serie el proceso de paz en Colombia 1980-2013. Tomo IX (pp. 75-148). Bogotá, Colombia: Fundación Cultura Democrática. Organización Internacional para las Migraciones.

Zibechi, R. (2007). Autonomías y Emancipaciones. América Latina en Movimiento. Lima, Perú: Fondo Editorial de la Facultad de Ciencias Sociales Unidad de Post Grado - UNMSM.

Zuluaga, J. (2013). Movimiento por la paz y contra la guerra. En Á. Villarraga (Comp.), Movimiento ciudadano y social por la paz. Biblioteca de la Paz. Serie el proceso de paz en Colombia 1980-2013. Tomo IX (pp.41-55). Bogotá, Colombia: Fundación Cultura Democrática. Organización Internacional para las Migraciones. 